\title{
trabalho
}

issn: 1808 - 799X

ano 9 - edição especial, número 13 - 2011

\author{
GRUPO DE PESQUISA TRABALHO - EDUCAÇÃO E EDUCAÇÃO \\ AMBIENTAL - GPTEEA (IFRJ)
}

\section{EDUCAÇÃO AMBIENTAL (EA) PARA ALÉM DO CAPITAL: ESTUDOS E APONTAMENTOS PARA A EA SOB A PERSPECTIVA DO TRABALHO}

\author{
Alexandre Maia do Bomfim - \\ Grupo de Pesquisa Trabalho-Educação e Educação Ambiental - GPTEEA \\ Instituto Federal de Educação, Ciência e Tecnologia do Rio de Janeiro - IFRJ
}

\section{Resumo}

Este trabalho, em parte é síntese de estudos do Grupo de Pesquisa TrabalhoEducação e Educação Ambiental (GPTEEA), noutra parte são alguns estudos antecedentes próximos à formação desse grupo. O presente texto teve a intenção de elencar algumas orientações que pudessem colocar a Educação Ambiental (EA) num caminho crítico, a partir de referenciais marxistas. Com isso foram alcançados alguns apontamentos à EA. Para a constituição de uma Educação Ambiental Crítica, vale considerar/apontar: o resgate do humanismo; os limites do "desenvolvimento sustentável"; a revisão permanente para evitar a conformação; o ataque permanente ao viés conservacionista; a crítica às ações higienizadoras e à culpabilização dos indivíduos; o questionamento ao consumismo (mais do que a mitigação dos resíduos); os principais responsáveis pela depredação ambiental, como também, por outro lado, os que realmente sofrem com as mazelas provocadas pela degradação ambiental; como sendo a conscientização ambiental insuficiente (pois a degradação não é ameaça ao sistema do capital); 
/indicar/ensaiar ações políticas, para além da educação, sejam elas conjunturais ou estruturais.

Palavras-chave: Educação Ambiental Crítica, Trabalho e Educação, Trabalho e Meio Ambiente, Capital e Meio Ambiente, Capital e Trabalho. 


\title{
1- Introdução
}

\begin{abstract}
Há uma palavra, uma palavra malvada, em que penso, sempre que penso sobre a estrutura do poder no mundo, e é "nkali". É um substantivo que livremente se traduz por "ser maior que outro". Como os nossos mundos econômico e político, também as histórias se definem pelo princípio do nkali. (Chimamanda Adichie, escritora nigeriana)
\end{abstract}

O que pretendemos aqui é apresentar um percurso teórico, que fizemos nos últimos anos, sobretudo com a contribuição de autores marxistas, para ler a "Questão Ambiental" na realidade contemporânea brasileira. Com esses autores, procuramos apreender essa temática sob a perspectiva do trabalho, naquilo que ofereceram para constituir uma leitura mais crítica, como também naquilo que não alcançaram e nos permitiram dar, em algum mínimo aspecto, uma continuidade.

\section{1- Dos apontamentos e considerações de trabalhos anteriores...}

Este texto foi construído, em parte, a partir dos estudos realizados pelo Grupo de Pesquisa em Trabalho-Educação e Educação Ambiental (GPTEEA), noutra parte, a partir de estudos realizados em momento anterior, mas próximo à constituição do grupo ${ }^{1}$.

O mote para os estudos e para as pesquisas sempre foi: refletir o mundo do trabalho e a questão ambiental de forma relacionada, mantendo a crítica à economia capitalista. O GPTEEA está vinculado ao Programa de Pós Graduação Stricto Sensu em Ensino de Ciências (Propec) do IFRJ, em que o apelo à Educação Ambiental se faz mais presente.Essa peculiaridade que circunscreve o grupo influenciou até o presente momento a se fazer mais estudos dentro da temática ambiental especificamente, do que em trabalho-educação. Não obstante,

\footnotetext{
${ }^{1}$ O GPTEEA (Grupo de Pesquisa em Trabalho-Educação e Educação Ambiental) foi instalado em 2009, na semana de Meio Ambiente, no Campus Nilópolis, do Instituto Federal de Educação, Ciência e Tecnologia do Rio de Janeiro. Seu início foi estimulado por alunos da pós-graduação Lato sensu em Proeja do IFRJ-Nilópolis. Hoje o grupo está ligado ao Programa de Pós Graduação Stricto Sensu em Ensino de Ciências (Propec) do IFRJ, conta com professores orientadores do Mestrado, alunos de graduação e pós-graduação. O grupo tem conquistado apoio do IFRJ, através de pequenos investimentos em alguns projetos, disponibilização de sala para reunião, divulgação em site, etc. O GPTEEA tem registro no Diretório de Grupos do CNPq.
} 
em tais estudos sempre se garante que o "trabalho" se destaque como categoria sociológica chave (cf. BOMFIM; PICCOLO, 2009).

\section{2- Nossos interlocutores (Lowy, Chesnais, Serfati, Mészáros, Furtado, Arrighi, Gramsci, Kosik, Konder, Manacorda, Frigotto...)}

Vale começar com a leitura de Löwy (2005), porque foi com esse ecossocialista que vimos a possibilidade de convergir o discurso entre vermelhos (marxistas) e verdes (ambientalistas). Não obstante, uma convergência que não é evidente, pois necessita de algumas reavaliações e novos posicionamentos. Enfim, uma contribuição importante de Löwy:

(...) foi mostrar que não é suficiente assumir espaços de produção e de poder dentro do capitalismo se for mantida a sua lógica. Por exemplo, não há nada de libertador se os trabalhadores assumirem uma fábrica de armas, (...) elas por si mesmas se propõem a atividades nefastas (...). (BOMFIM, 2008, p. 10)

Não obstante, o limite de Löwy foi acreditar que a degradação ambiental seria a segunda contradição para o capital (semelhante ao que acontece com a exploração do trabalho, que é a primeira contradição). Agora com a leitura de Chesnais; Serfati (2003), alcançamos que:

A escassez da natureza não é uma ameaça ao sistema capital, porque será essa mesma escassez que proporcionará bons novos negócios. Quanto mais a natureza se exaurir, mas se vislumbra a possibilidade de mercantilizar a água, o ar, a beleza, o que restar do verde, dos animais, etc. O sistema do capital é capaz de destruir primeiro a natureza, o ser humano, do que a si mesmo. (ibid., p.10)

Aqui vão nossos primeiros apontamentos à Educação Ambiental (EA), que deve considerar: [1] a necessidade de resgate permanente do humanismo (como acontece no marxismo); [2] a tarefa de denúncia, não somente das mazelas impostas pelo "sistema do capital" (MÉSZÁROS, 2002), mas também das formas de camuflá-las; a denúncia dos [3] limites do desenvolvimento sustentável; [4] a importância de manter constantemente revisão de sua prática, porque a EA tende à conformação quando o horizonte não é o embate político.

E sobre o que fica em aberto, é o que mais nos interessa aqui:

A questão ambiental é um dos elementos de uma nova pauta e ainda que não chegue a constituir uma $2^{\underline{a}}$ contradição imprime (...) desafios teórico-práticos. Não nos parece que a luta dos trabalhadores possa ainda desconsiderar a questão ambiental; de que a crença no desenvolvimentismo (por vezes também encontrado em Marx) não possa ser 
relativizada; de que em sua luta por sobrevivência, os menos abastados também não possam e já estejam oferecendo novas respostas à degradação ambiental... (BOMFIM, 2008, p.13)

Quer dizer, o desafio a ser enfrentado é assumir a Questão Ambiental dentro de uma perspectiva crítica, desvencilhando-se do viés desenvolvimentista, mas com novas respostas aos trabalhadores e a partir deles...

Noutro trabalho, após releitura de Furtado (1974, 2003) e Arrighi (1997, 1998) à questão ambiental nos países subdesenvolvidos, alcançamos, em uma de nossas conclusões, que:

(...) não vai haver reversão alguma dentro de um sistema societário [capitalismo] que mantém acumulação de riquezas para alguns; expropriação do trabalho e dos recursos naturais; e que se estabelece na administração da escassez de muitos (...) (BOMFIM, 2010, p. 15).

O que nos levou a um impasse:

“(...) reivindicar o direito de poluir, de consumir, de destruir como fizeram os países centrais não é o caminho. Talvez não saibamos o que fazer, mas definitivamente sabemos o que não deve ser feito." (ibid).

$\mathrm{Na}$ busca de aprofundar as contradições, nossas leituras foram nos permitindo construir os elementos para o que seria uma "Educação Ambiental Crítica" (EA-CRÍTICA), sem que isso significasse apenas um jargão.

Seria muito importante que EA alcançasse grau máximo de crítica (...), [5] saísse do patamar da higienização e culpabilização simplista de todos os indivíduos para: (...) [6] questionar o incentivo consumista da sociedade capitalista [em vez de colocar como ponto de chegada a reciclagem do lixo e a mitigação dos resíduos]; (...) [7] apontar os principais responsáveis pela degradação ambiental; (...) mostrar que o aumento no nível de consciência da crise ambiental proporcionalmente não a diminuiu; (...) lembrar que, embora democratizada a responsabilidade, a [8] experimentação das mazelas advindas da destruição da natureza não é (...) igualitária, pois os pobres a sentem mais; (...) [9] mostrar até que a destruição da natureza não ameaça o "sistema do capital" (...), porque exatamente a escassez dos recursos que possibilita a realização de bons negócios (...). (BOMFIM; PICCOLO, 2009 p. 8)

$\mathrm{Na}$ continuação dos estudos, agora para refletir a Legislação Ambiental (LA) na relação com a Educação Ambiental, vimos mais um problema para a EA que se mantém sob a perspectiva conservacionista e conservadora:

Precisamos obter uma lei que comece a rever o convívio homem-natureza, porque senão dificilmente vamos reverter o atual quadro de degradação da natureza. Ainda que essa reflexão passe por dúvidas, disso ser ou não utópico, de ser ou não possível no interior da sociedade capitalista, o fato é que precisamos reorientar nossa EA, até a [Legislação Ambiental] LA e as políticas públicas num sentido de recuperar o homem como sendo um "ser natural", que não fica em oposição à natureza ou como sendo geneticamente poluidor. [10] Garantir áreas à preservação e outras à poluição é uma 
orientação equivocada, a não ser que as primeiras crescessem exponencialmente, mas não é isso que se tem visto e nem é isso que vai acontecer na atual configuração do Estado capitalista. (p.1)

Nessa perspectiva crítica, indica-se à EA que se faça, se realize, para além do próprio espaço formal educacional, para além da escola, [11] indicando os embates políticos possíveis, sejam estruturais ou conjunturais, “(...) vai ser necessário assumir os órgãos de poder para lhes dar outros direcionamentos, para não somente obter mudança formal na legislação, mais um novo enfoque sobre a economia e a política" (BOMFIM; PICCOLO, 2009, p. 8, grifos nossos).

Não obstante, também essas leituras acima nos deixam uma consideração importante para as reflexões ascendentes:

(...) nossas referências à Educação Ambiental Crítica, provavelmente em breve precisarão ser revistas, poderão até se apresentar insuficientes, por ora são importantes porque tangem o que é estrutural ao atual modelo societário, causa de nossos problemas sócio-ambientais: a expropriação do trabalhador, a mercantilização de tudo e a proteção da propriedade privada. É necessário romper com essa estrutura, ainda que a degradação ambiental não seja uma contradição para o sistema do capital é para os homens. (ibid., p. 8)

Qual o desafio à EA-CRÍTICA? É fazer a crítica ao sistema do capital (nesses três pilares: expropriação do trabalho, mercantilização de tudo e proteção à propriedade privada), por dentro do próprio sistema. Quer dizer, o mesmo desafio clássico da pedagogia crítica, sobretudo na tradição marxiana e gramsciana (cf. MANACORDA, 2007) no capitalismo ocidental. Porém, com um agravante: a degradação ambiental não coloca em risco o desenvolvimento e a lógica do sistema do capital. No mínimo isso significa que o item "meio ambiente" até pode entrar na pauta do Capital, mas para valer só tardiamente. Com isso, provavelmente só uma perspectiva humanista para a EA-CRÍTICA, para além do sistema do capital, poderá obter algum resultado favorável ao meio ambiente. Como a EA-CRÍTICA poderia se realizar nessa direção? Há como superar o plano do discurso, sem desqualificar esse lugar de reflexão sobre a relação homem e natureza?

\section{2- Ensaios à Educação Ambiental Crítica, com a ajuda de Mészáros}

A proposta desta parte do texto é tomar cada um dos 11 itens levantados na introdução (que já são inferências de estudos anteriores) para voltar a refleti- 
los, mas em diálogo com a visão do marxismo contemporâneo do autor István Mészáros.

\section{I- Resgate do Humanismo.}

Ao mesmo tempo em que se resgata o homem quanto "ser da natureza", pode ser politicamente estratégico devolver-lhe a condição de "ser da cultura", porém com uma concepção de cultura construída a partir e através do trabalho, da relação homem-natureza, do fazer e refazer do ser, do movimento histórico...

Um sistema de controle que aceita sem questionar a inalterabilidade de seus próprios parâmetros não pode escapar à fatídica contradição de tornar absoluto o relativo e, ao mesmo tempo, decretar a permanência do que na realidade só pode ser transitório. (MÉSZÁROS, 2002, p. 133).

Onde o capitalismo é apenas uma das possibilidades de expressão de sociabilidade humana e não-perene.

\section{II- Denúncia e desmitificação do sistema do capital.}

\section{III- Limites do “Desenvolvimento Sustentável”.}

O item certamente importante à EA-CRÍTICA é mostrar a relação entre o sistema do capital com a degradação ambiental, sem alarde, apontando as relações de exploração, expropriação, acúmulo excessivo, desperdício, exclusão, etc.

Uma das funções principais da educação formal nas nossas sociedades é produzir tanta conformidade ou "consenso" quanto for capaz, a partir de dentro e por meio dos seus próprios limites institucionalizados e legalmente sancionados. (MÉSZÁROS, 2005, p. 45).

No mínimo, questionar a manutenção da lógica desenvolvimentista associada à sustentabilidade. Denunciar essa falsa idéia de "sustentabilidade" geralmente colocada para o futuro, em que para o presente fica apenas a tarefa de não esgotar os recursos naturais. Uma idéia de sustentabilidade que credita sempre no avanço tecnológico como capaz de reverter quadros de degradação, poluição...

\section{IV- Revisão permanente para evitar a conformação.}

\section{V- Crítica à perspectiva conservacionista e conservadora da EA.}




\section{VI- Crítica à EA que se reduz a ações higienizadoras e de simples culpabilização dos indivíduos.}

Para a EA se fazer Crítica é importante tomar cuidado com um caminho que está sempre em seu entorno, na verdade da Educação de maneira geral: a reprodução do sistema.

É por isso que hoje o sentido da mudança educacional radical não pode ser senão o rasgar da camisa-de-força da lógica incorrigível do sistema: perseguir de modo planejado e consistente uma estratégia de rompimento do controle exercido pelo capital, com todos os meios disponíveis, bem como com todos os meios ainda a ser inventados, e que tenham o mesmo espírito. (MÉSZÁROS, 2005, p. 35).

Isso pode acontecer por variadas formas, principalmente: a) ao dar mais atenção aos efeitos do que às causas (a produção do lixo, por exemplo, em vez do consumo); ou quando orienta mais às ações individuais, comportamentais sem mostrar a maior degradação realizada pelos governantes e pelas grandes corporações; no momento que fica na dimensão conservacionista (em que se garantem lugares para preservar e conseqüentemente outros para poluir)...

\section{VII- Questionamento do consumismo na Sociedade capitalista e o reducionismo da EA que só trata da reciclagem dos lixos e mitigação dos resíduos.}

O que não significa desprestigiar o tratamento do lixo, mas trabalhar que sendo apenas uma das indicações para diminuir a degradação da natureza.

\section{VIII- Denúncia: os principais responsáveis pela depredação ambiental. \\ IX- Quem realmente sofre com as mazelas provocadas pela degradação ambiental.}

Incrementar a perspectiva de classe: hierarquizar os agentes poluidores segundo sua capacidade de poluição e segundo suas responsabilidades de reverter o quadro de depredação do meio ambiente, também podem ser elementos da EA-CRÍTICA.

Há dez anos a ecologia podia ser tranquilamente ignorada ou desqualificada como totalmente irrelevante. Atualmente, ela é obrigada a ser grotescamente desfigurada e exagerada unilateralmente para que as pessoas (...) possam ser, com sucesso, desviadas dos candentes problemas sociais e políticos. (MÉSZÁROS, 2002, p. 987). 
Mostrar quem realmente sofre com a degradação e quem não pode transferir seus efeitos: os pobres. Estes que moram nas encostas dos morros, ao lado do mangue e rio poluídos, moram próximo ou trabalham nas fábricas que expelem toxinas. Os mesmos que são responsabilizados igualmente aos ricos pelos problemas ambientais, embora participem bem menos da lógica consumista do sistema.

\section{$X$ - Conscientização ambiental não é suficiente, pois a degradação ambiental não é ameaça ao sistema do capital.}

Tarefa árdua para a EA-CRÍTICA dizer que a conscientização é insuficiente, já que um dos seus propósitos é a "conscientização", não obstante, esse posicionamento é importante para fazer a EA efetivamente Crítica, porque a Educação não explica em si mesma, não é ponto de chegada, mas de partida. "Do mesmo modo, contudo, procurar margens de reforma sistêmica na própria estrutura do sistema do capital é uma contradição em termos" (MÉSZÁROS, 2005, p. 27).

Uma EA-CRÍTICA pode encontrar espaço diante da "deseducação" promovida pelos setores filiados ao desenvolvimentismo e consumismo. $O$ agravante é ter a compreensão de que o capital não se desvaloriza com a degradação da natureza. Claro que o capital não prescinde da escola, como vimos com Frigotto (1993) na "produtividade da escola improdutiva", mas a degradação ambiental, como vimos com Chesnais; Serfati (2003) pode até valorizar o capital. "É por isso que é necessário romper com a lógica do capital se quisermos contemplar a criação de uma alternativa educacional significativamente diferente" (ibid., 2005, p. 27).

Indicar, ensaiar as ações políticas, para além da Educação, sejam elas conjunturais ou estruturais. Como nos exemplos feitos abaixo, com medidas políticas e econômicas para um novo enfoque que:

(...) [a] priorize a distribuição em relação à concentração de renda; não reivindique o "direito de poluir" para se desenvolver; [b] busque justiça social imediatamente e não a vislumbre só para o futuro; [c] redirecione o "desenvolvimento" tecnológico à diversificação e aos elementos que impactam menos à natureza; [d] impeça de transformar a escassez da natureza em negócio; [e] não permita que o direito natural de reprodução da vida pelos grupos humanos se dê exatamente pela depredação de seu 
ambiente. [Entre outros pontos.] Ou seja, a "Questão Ambiental" é no fundo uma "Questão sócio-político-econômico-ambiental” (...). (BOMFIM, PICCOLO, 2009, p.8)

Assim, encaminhamento interessante à EA-CRÍTICA é arriscar em apontar ações políticas noutros espaços além da Educação formal.

Sem um progressivo e consciente intercâmbio com os processos de educação abrangentes como "a nossa própria vida", a educação formal não pode realizar as suas muito necessárias aspirações emancipadoras. Se, entretanto, os elementos progressistas da educação formal forem bem-sucedidos (...) poderão dar uma contribuição vital para romper a lógica do capital, não só no seu próprio e mais limitado domínio como também na sociedade como um todo. (MÉSZÁROS, 2005, p. 27).

A síntese dos apontamentos alcançados até agora, para uma EA-CRÍTICA, pelo GPTEEA, surgiu da contribuição das Ciências Sociais, correspondendo, em parte, ao chamado feito por Layrargues (2002), que propôs à Sociologia que também assumisse a Educação Ambiental. Estamos fazendo isso, sob a perspectiva do trabalho.

\section{XI- Em busca das aspirações emancipadoras...}

O que se alcançou com os apontamentos, acrescidos da contribuição de Mészáros foi que, grosso modo, a principal orientação para constituir uma EA "crítica" é ir além dos próprios muros da educação formal. Mészáros chega a dizer que "(...) muito do nosso processo contínuo de aprendizagem se situa, felizmente, fora das instituições educacionais formais" (2005, p. 53). Claro que no seu juízo de valor com o termo "felizmente" carrega uma leitura do marxismo de que: é importante sempre ter uma relação desconfiada com a escola (também nossa visão), porque possivelmente ela é reprodutora do sistema do capital. Por outro lado, ter essa relação desconfiada é exatamente para não condená-la definitivamente, mas garantir uma "direção à perspectiva de uma alternativa hegemônica à ordem existente" (ibid. p. 27). Não obstante, ao Mészáros acrescentaríamos à sua frase o termo "infelizmente", assim: "felizmente e infelizmente", porque não é sempre, nos espaços não-formais e informais de ensino $^{2}$ que acontece a "alternativa hegemônica", pois acontece muitas vezes o contrário: estabelecimento da própria hegemonia do capital. O que se vê nas novelas, na grade inteira das redes de TV, na publicidade, na mídia impressa, nos

\footnotetext{
${ }^{2}$ Sobre a diferenciação entre espaços, formais, não-formais e informais de ensino, vale conferir Gohn, 2010.
} 
entretenimentos de massa de maneira geral, nas orientações políticas, nas leis, nos apologetas da economia das empresas, senão a pedagogia do capital?

Uma Educação que se quer crítica deve, de seu espaço (no caso formal), desmitificar, desvelar, esmiuçar o conteúdo apologético que acontece em todos os espaços (no seu e nos outros) de ensino utilizados pela pedagogia do capital. E nossa hipótese é de que a EA-CRÍTICA pode fazer isso de forma emblemática, por algumas características, a seguir.

De imediato, vale posicionar que, paradoxalmente, por não ser a problemática ambiental uma contradição para o desenvolvimento do capital, faz com que não haja ações (nem mesmo concessões ${ }^{3}$ ) concretas à preservação da natureza, mas somente ações pseudoconcretas (cf. KOSIK, 1986). A primeira tarefa da EA-CRÍTICA é destruir essa pseudoconcreticidade ${ }^{4}$. Como a crise ambiental é resultado da possível crise capitalista, mas não o contrário, a EACRÍTICA poderia escancarar ainda mais a "fatal incontrolabilidade do sistema do capital" (cf. MÉSZÁROS, 2002) que, no final das contas, não está preocupado com a preservação da natureza. Na verdade, no capitalismo, o Estado tem tarefas anteriores à preservação da natureza: a manutenção da sociedade de classes e controle do trabalho ${ }^{5}$, a busca incessante por lucro e expansão. O que a EACRÍTICA pode fazer é denunciar a praxis utilitarista do capitalismo, em que mede tudo sob a curta racionalidade de custos e benefícios, e ainda de forma piorada

\footnotetext{
${ }^{3}$ Como acontece relativamente, em alguns períodos históricos em relação ao trabalho: "As concessões dadas ao trabalho pelo 'Estado de bem-estar social' não debilitaram em absolutamente nada o capital. (MÉSZÁROS, 2002, p. 919)

${ }^{4}$ Vale uma noção melhor sobre o que isso significa: "Não podemos, por conseguinte, considerar a destruição da pseudoconcreticidade como o rompimento de um biombo e o descobrimento de uma realidade que por detrás dele se escondia, pronta e acabada, existindo independentemente da existência do homem. A pseudoconcreticidade é justamente a existência autônoma dos produtos do homem e redução do homem ao nível da praxis utilitária. A destruição da pseudoconcreticidade é o processo de criação da realidade concreta e a visão da realidade, da sua concreticidade." (KOSISK, 1986., p. 19)

${ }^{5} \mathrm{O}$ capital é o modo de controle mais amplamente alienado da história, com sua estrutura de comando auto-incluída, pois tem que operar pela estrita subordinação dos produtores - em todos os espaços - a um sistema de tomada de decisão radicalmente divorciado deles. Esta é uma condição irremediável, devido ao caráter totalizador - e, em suas implicações objetivas, globalmente expansionistas desde o início - do sistema que não pode compartilhar o poder, nem mesmo em grau mínimo, com trabalho. (MÉZSÁROS, 2002, p. 935)
} 
porque só considera como parâmetros o "valor de troca" e os critérios de escolha da "mão invisível" do mercado 6 .

A EA-CRÍTICA pode mostrar a irracionalidade do sistema - por não receber concessões concretas - apontar a ineficácia dos programas de política ambiental, as ações paliativas, as inconsistências do mercado livre, a necessidade infinita de produzir supérfluos na busca do lucro e valorização do capital, etc. A EA-CRÍTICA pode mostrar que apesar da maior conscientização ambiental e com algum reflexo nas leis e nas políticas ambientais, o processo de degradação ambiental é contínuo, pode até passar por refluxos, mas tende a impactar agressivamente a biodiversidade até quase sua obliteração. Quer dizer, a vocação nefasta do sistema do capital (sem que sejamos escatológicos) no fim é: o fim da humanidade.

Pois, nos termos da lógica do capital, exterminar a humanidade é muito preferível a permitir que se questione a causa sui desse modo de reprodução. Na medida que a dissipação veloz e destrutiva dos recursos materiais e humanos, e também dos produtos do trabalho, adquire uma conotação perversamente positiva no sistema do capital em crise estrutural, representando as "condições de sua autopreservação", a alternativa socialista que visa a superar a escassez deve ser um anátema para os ideólogos da ordem prevalecente. (MÉZSÁROS, 2002, p. 952)

Contudo, não será o fim da natureza, pois o que restar da natureza, ainda assim será natureza. De outra forma, pode ser que não alcancemos a tão vocação (fim da humanidade), mas o que restará? Que animais nos acompanharão? Que verde sobrará? Que clima alcançaremos? Só os animais que estiverem a nós subordinados sobreviverão? Os ambientes artificializados prevalecerão?

A contrapartida que EA-CRÍTICA pode oferecer aos trabalhadores é mostrar os momentos em que sua luta se faz míope. Míope, quando - assim como a pedagogia do capital - ataca os efeitos e não as causas, quando - por conta de legítima luta imediata e de contexto local - não consegue enxergar mais ao longe e à estrutura. Como acontecem nos casos de luta de funcionários de

\footnotetext{
${ }^{6}$ Para continuarmos em Mészáros (2002) vale um exemplo de irracionalidade que mostra o desinteresse pelas pessoas e pelo ambiente: "A economia do sistema do capital se assemelha à indústria britânica de água em que (...) é 'muito mais econômico' deixar que os canos desperdicem toda aquela água [referindo-se a vazamentos na rede de água] do que reparar ou renovar a própria rede de distribuição defeituosa; uma política seguida, dizem eles, 'estritamente no interesse dos consumidores'” (p. 946).
} 
madeireira ${ }^{7}$, como nos casos dos catadores de lixo que temem pelo fim dos lixões ${ }^{8}$, etc. Esses "trabalhadores que margeiam a degradação ambiental" querem salvar a qualquer custo seus empregos, mesmo quando são precarizados. Destarte, é uma reflexão que também vale para os trabalhos que assim não se vêem imediatamente, nem precarizados e nem na fronteira da degradação.

No que se refere à própria temática ambiental, a EA-CRÍTICA pode combater o conteúdo e os intelectuais orgânicos de sua antagonista, a Educação Ambiental Conservadora (EA-CONSERVADORA); em todos os momentos que ela se fizer presente, nos espaços formais, não-formais e informais de ensino. $O$ papel da EA-CONSERVADORA seria fornecer a "consciência ecológica" para a mudança de rota $^{9}$. Essa proposta de educação aparece como panacéia à degradação ecológica. Dessa forma, a educação põe-se neutra, positivista, redentora, não está considerando o conflito de interesses, como se o ato educativo por si mesmo estivesse imune aos elementos de reprodução ${ }^{10}$.

\section{3- Considerações à Educação Ambiental Crítica: Questões em aberto}

\footnotetext{
${ }^{7}$ Funcionários do setor madeireiro em Feliz Natal (130km de Sinop) [em Mato Grosso] não vão trabalhar amanhã pela manhã e participarão de uma mobilização, em protesto contra a prisão de alguns empresários, donos de madeireiras, durante a operação Mapinguari, que resultou, em todo - Estado, na detenção de 47 suspeitos de envolvimento com extração ilegal de madeira. Os funcionários também protestarão contra a demora na concessão de novas licenças e autorizações para extração de madeira, que vem afetando o trabalho das indústrias. Cerca de 3,5 mil manifestantes são aguardados. O setor responde pela maioria dos empregos formais do município e é a principal base econômica. De acordo com a categoria, algumas empresas já começaram a sentir os reflexos negativos da situação e já estão despedindo funcionários. "Só Notícias" apurou que no município são mais de 50 empresas, e cada emprega uma média de 190 pessoas. $\mathrm{Na}$ semana passada, o prefeito Manuel Messias Sales disse que caso nenhuma providência seja tomada no sentido de viabilizar o pleno exercício da atividade madeireira em Feliz Natal, deve ser decretada situação de emergência no município, paralisando todos os serviços por 15 dias. (FUNCIONÁRIOS, 2007)

8 "Catadores de Gramacho temem perder o sustento com o fim do lixão" (PLATONOW, 2011)

${ }^{9}$ Mesmo quando essa EA Conservadora chega ao patamar do "Desenvolvimento Sustentável", o cálculo é simplista: (a) a natureza está sendo degradada; $(+$ b) os homens fazem isso externamente à ela, através da poluição, depredação e excesso de população; $(+\mathrm{c})$ assim, ao se controlar a ação dos homens $(=d)$ se recuperará a natureza para as gerações futuras.

${ }^{10}$ Veicula-se neste momento (primeiro semestre de 2011) em algumas salas de cinema no Brasil uma propaganda de como cada pessoa e/ou empresa pode neutralizar suas emissões de carbono (caracterização explícita do mercado verde): plantando árvores! A proposta de tal organização, que tem o sugestivo nome "Banco da Árvore", é fazer isso por quem contratar os seus serviços. No site cada pessoa pode calcular quantas árvores são necessárias por ano, para neutralizar suas emissões, quanto pessoa física ou jurídica, sem precisar sair de casa, pagando com cartões de crédito ou boleto bancário. Uma forma bem apropriada ao sistema do capital para agir "ecologicamente correto" e continuar consumindo. (cf. www.bancodaarvore.com.br)
} 


\section{1- Como se desvencilhar do caminho desenvolvimentista com novas respostas aos trabalhadores e a partir deles? Não reivindicando o direito de poluir, de consumir, de destruir como fizeram os países centrais, $o$ que fazer?}

Quando em muitos momentos criticamos os "espaços de ensino da pedagogia do capital" por uma EA-CONSERVADORA, por exemplo, que dá maior enfoque ao lixo do que ao consumo, não podemos desconsiderar que muitos trabalhadores ainda não alcançaram um patamar mínimo de consumo e que, antes de tudo, possuem o direito inalienável de reproduzir sua própria vida. Como também não podemos abrir mão da compreensão de que a "poluição dos ricos" foi e continua sendo mais significativa do que a "poluição dos pobres". Não obstante, a questão: os pobres devem reivindicar o direito de poluir na busca de desenvolvimento? (cf. BOMFIM, 2010).

Atentos a isso, ambientalistas críticos já apontam há algum tempo que a "justiça social" deve ser uma meta da luta política ambiental e de que sobre os ricos (pessoas e países) se estabeleça um "teto de consumo material" (cf. LAYRARGUES, 1997). Claro que essa visão não obteve sucesso, claro que não obteve adesão dos ricos, porém, o interessante, foi não obter também a adesão dos mais pobres... No Relatório Brundtland, encomendado pela ONU, alcançouse apenas a idéia de "piso de consumo material" e "Desenvolvimento Sustentável" (Ibid.), conceitos comprometidos com a sociedade de consumo e a lógica do capital. Pedir para que os ricos consumam menos a favor dos pobres, ou que haja redistribuição são elementos de um discurso romântico. O sistema do capital, como vimos em Mészáros (2002), obterá sempre suas "personificações" para representá-lo e garantir sua manutenção. A reação precisa vir do próprio trabalho. Não dá para esperar pela benevolência do Capital.

O problema é que muitas vezes há por parte dos próprios trabalhadores uma filiação ao desenvolvimentismo. Isso fez Löwy (2005), mostrar que não é óbvia, embora pudesse ser (por conta da crítica ao sistema do capital), a conciliação entre a luta dos trabalhadores (os vermelhos) com os ambientalistas (os verdes). 
Alguns trabalhos começam considerar a ótica dos pobres (cf. Martinez Alier, 2004), mas esse tipo de estudo tem que ser ampliado, também para entendimento do trabalhador urbano e países periféricos.

\section{2- Qual o discurso (considerando a materialidade) mais avançado para a EA?}

A partir da leitura de Kosik, alcançamos também a seguinte questão: “(...) as coisas que a nós se apresentam não poderiam estar de outra forma?" (BOMFIM, 2008, p. 5) Esse é o mote inicial para a construção permanente de um discurso mais crítico e que se coloca no terreno da praxis revolucionária. $\mathrm{O}$ mundo é o mundo que se pratica...

Ao contrário do mundo da pseudoconcreticidade, o mundo a realidade é o mundo da realização da verdade, é o mundo em que a verdade não é dada e predestinada, não está pronta e acabada, impressa de forma imutável na consciência humana: é o mundo que a verdade devém. (KOSIK, 1986, p. 19).

Colocar a EA-CRÍTICA no terreno da praxis revolucionária é garantir-Ihe movimento, dialética, relação teoria e prática... Porém, mais do que anunciar termos e jargões, o mais importante é destituir a EA de seu viés conformador, reprodutor do sistema do capital.

Somos seres de carne e osso, seres vivos, engajados na aventura de viver. Existimos agindo, tomando decisões, fazendo escolhas, tomando iniciativas, trabalhando, utilizando na nossa atividade o imprescindível (embora precário) conhecimento disponível. É na prática, na realização dos nossos projetos, que checamos a justeza de nossos pensamentos e a verdade dos conhecimentos em que nos apoiamos (KONDER, 2002, p. 261).

Checar a "justeza de nossos pensamentos" também é pertinente à EACRÍTICA, isto significa: saber se eles se realizam; como também na mão inversa, significa: revisá-los permanentemente.

Uma "EA para além do capital" é aquela que, tomada as precauções de vigiar seu espaço de origem, denuncia todas as camuflagens, fetiches, do mundo reificado. Toma para si todos os espaços educativos (formais, não-formais e mesmo informais) em que a pedagogia do capital se faz presente para realizar outra verdade.

\section{3- O que cabe à EA-CRÍTICA?}


A Educação que se pretende "Crítica" (não nos referimos apenas à EA) tem desafios muito grandes, alguns quase intransponíveis. Há, por exemplo, a leitura dentro do marxismo que chega a dizer:

[Sobre] (...) as instituições de ensino [uma primeira conclusão é de caráter negativo:] não são o lugar a partir do qual pode se desencadear a transformação revolucionária da sociedade como um todo. A escola não deve ser encarada como o centro irradiador do processo da revolução. (KONDER, 2001, p. 20).

Como a Escola, por exemplo, faz parte da superestrutura, não dá para esperar que desse plano seja possível a transformação da estrutura econômica. Por outro lado, nenhuma visão pode ser fixa e monolítica, mesmo porque a escola pode ser "(...) um campo de batalha importante, onde se pode inculcar hábitos conservadores (...), mas onde se pode também fortalecer disposições críticas (...)." (ibid., p. 21). Destarte, onde começa a revolução? Não se pode esperar muito da escola burguesa, mas pode se esperar muito de qual outro espaço? A escola é um dos campos de batalha e não o único (nem quanto espaço educativo) que também carrega inúmeras contradições que podem ser exploradas pelo educador crítico.

O sistema do capital precisa, para sua reprodução na contemporaneidade, dar conhecimento ao trabalhador, o problema é que não pode lhe dar integralmente. A EA-CRÍTICA tem que tomar para si essas contradições e o que o sistema quer negligenciar. A EA-CRÍTICA, seja do espaço formal ou não-formal, precisa desconfiar dos temas que the atribuem e tomar para si os temas da sociedade que não querem problematizar, como: consumo e consumismo, utilização de energia, agronegócio, monopólios dos recursos naturais, latifúndio, monocultura, reforma agrária, moradia, reforma urbana, saneamento básico, justiça social, produtivismo, desenvolvimentismo, desigualdade social, mercado verde, publicidade verde, conteúdo midiático verde, políticas ambientais, legislação ambiental, economia e meio ambiente, etc. Uma Educação só se faz crítica se for à direção da sociedade...

Não obstante, como superar o plano do discurso? Por vezes é desolador saber que mesmo a EA-CRÍTICA fazendo as orientações acima, consegue obter muito pouco, em termos de eficiência e eficácia ecológicas. A EA-CRÍTICA, nesta perspectiva materialista, deseja apreender a realidade e mostrá-la, mas ela 
concorre com os aparelhos hegemônicos que vão se aperfeiçoando com a força do capital, mas, que podem também estar acentuando as contradições. $O$ problema é que em relação às questões ambientais, quando os homens desejarem obter novamente o comando, pode ser tarde demais. Isso é uma inferência, não é um alarde.

Uma EA-CONSERVADORA, ora coloca as reflexões e ações num plano estratosférico (preocupação com o "aquecimento global"), ora coloca num plano individual (controle do lixo doméstico), esvaziando o que é substancial em termos ecológicos. No Brasil, por exemplo, a emissão de gases de efeito estufa (GEE), por exemplo, se dá assim:

(...) setor de agricultura e pecuária representa aproximadamente $25 \%$ das emissões brasileiras atuais, percentagem que deve aumentar para $30 \%$ (...) até 2030. (...)

A maior parcela vem, no entanto, do setor florestal. O desmatamento, principalmente do bioma Amazônia, é a maior fonte de emissões de GEE do Brasil sendo responsável por 55\% das emissões atuais. Esse percentual deve cair para 43\% em 2030. (MCKINSEY\&COMPANY, 2010)

Quer dizer, 80\% dos GEE no Brasil não advêm do setor urbano. Como a EA-CRÍTICA deve tratar desse caso? Podemos liberar os moradores e trabalhadores urbanos à poluição? Uma EA-CRÍTICA deve mostrar a relação da cidade com o setor rural, de como este está subordinado, de como corresponde às demandas de nossas cidades e do capital externo. Aproveitar também para mostrar como é relativa a ação do indivíduo frente a outras muito mais necessárias, correspondentes ao Estado. Ou como a ação individual pode buscar outras possibilidades: como a dos boicotes, a diminuição no consumo de carne, de madeira, etc. Entendendo-se que "boicote", "diminuição de consumo" não são termos bem aceitos pela sociedade de mercado, pois são orientações que comprometem o sistema...

[O trabalhador] pensa assim: eu não vou fazer a compra porque eu tenho medo de perder o emprego. O que eu quero dizer é que ele corre o risco de perder o emprego, se ele não comprar porque ele não comprando o comércio não encomenda para indústria, que não produz, e sem produzir, não tem emprego [na indústria]. (Presidente Luís Inácio Lula da Silva em 2008, sobre a crise que abateu a economia mundial no final da primeira década do sec. XXI, apud BOMFIM, 2010, p. 11)

A lógica do sistema do capital compromete até mesmo o trabalho. $\mathrm{Na}$ passagem acima o presidente Lula conclama os trabalhadores a consumir para 
evitar ou diminuir os efeitos de um revés recente do capitalismo global. Sempre que for necessário o capitalismo vai usar desse expediente, a natureza está em segundo plano. Os ambientalistas críticos a essa relação econômica (de promoção do consumo) são vistos como empecilhos a serem superados, românticos, ideólogos da causa verde e não dos trabalhadores... Mesmo que esses ambientalistas não se posicionem biocêntricos, mesmo que também estejam alinhados à luta dos trabalhadores, o sistema do capital hipostasia o problema, evita que haja questionamento à própria economia (do consumo excessivo, da desigualdade, da acumulação, da produção de supérfluos, da dominação do campo, etc.) para exatamente se opor a quem trava o desenvolvimento. Definitivamente: não há conciliação entre a economia capitalista e preservação da natureza, essa é uma proposição bem diferente do que alcançou o ex-vicepresidente americano Al Gore no seu filme "Verdade Inconveniente" (VERDADE, 2006). No fim das contas, precisamos de "outra economia", de "outra sociedade"...

\section{Referências}

ARRIGHI, Giovanni. O longo século XX. São Paulo: UNESP, 1998.

. A llusão do Desenvolvimento. Petrópolis: Vozes, 1997.

BOMFIM, A. M.; ANJOS, M. B.; FLORIANO, M. D.; FIGUEIREDO, C. S. M.; SANTOS, C. L. de C. Uma Revisita aos Temas Transversais, Meio Ambiente e Ambiente: estudo sobre o legado dos PCN. Grupo de Pesquisa em TrabalhoEducação e Educação Ambiental (GPTEEA). Instituto Federal de Educação, Ciência e Tecnologia do Rio de Janeiro (IFRJ). mimeo. Nilópolis, 2011.

BOMFIM, A. M. ; PICCOLO, F. D. Educação Ambiental Crítica: para além do positivismo e aquém da metafísica. VII Enpec. Anais. Florianópolis: Abrapec, $2009 . \quad$ Disponível em: http://www.foco.fae.ufmg.br/viienpec/index.php/enpec/viienpec/paper/viewFile/753 $\underline{1648}$ 
BOMFIM, A. M. O (Sub)Desenvolvimento (In)Sustentável: A Questão Ambiental nos países periféricos latino-americanos. In: Trabalho Necessário, Rio de Janeiro, ano 8, $n^{\circ} 10$. Rio de Janeiro, UFF, 2010

- Que fazer diante da Legislação Ambiental? (Desde o Código Florestal de 1965): alguns apontamentos aos Educadores. Pôster. Seminário Latino-Americano sobre Interdisciplinaridade no Ensino de Ciências da Natureza SLIEC. Universidade Federal da Integração Latino-Americana - UNILA. Foz do Iguaçu, Paraná, 8-11 de dezembro de 2010b.

. Trabalho, Meio Ambiente e Educação: apontamentos à Educação Ambiental a partir da Filosofia da Práxis. In: XIV ENDIPE, 2008, Porto Alegre. XIV ENDIPE. Porto Alegre : EDIPUCRS, 2008. p. 1-14.

CHESNAIS, F.; SERFATI, C. "Ecologia" e condições físicas de reprodução social: alguns fios condutores marxistas. Crítica Marxista. no 16. São Paulo: Editora Boitempo, 2003.

FRIGOTTO, G. A Produtividade da Escola Improdutiva. São Paulo: Cortez, 1993.

FUNCIONÁRIOS de madeireiras em Feliz Natal protestam e param as atividades amanhã. Repórter news. 28 maio 2007. Disponível em: http://www.reporternews.com.br/noticia.php?cod=189753. Acesso em 10 de fevereiro de 2011.

FURTADO, C. Raízes do Subdesenvolvimento. Rio de Janeiro: Civilização Brasileira, 2003.

.O Mito do Desenvolvimento Econômico". Rio de Janeiro: Paz e Terra, 1974.

GOHN. M. da G. Educador Não Formal e o Educador Social. São Paulo: Cortez, 2010.

KOSIK, K. Dialética do Concreto. 1ª. Impressão em 1972. Rio de Janeiro: Paz e Terra, 1986.

LAYRARGUES, P. P. Muito Prazer, Sou a Educação Ambiental, seu Novo Objeto de Estudo Sociológico. In: Anppas, I Encontro da Associação Nacional de Pós- 
graduação e Pesquisa em Ambiente e Sociedade, 6 a 9 novembro de 2002 $\begin{array}{lllll}\text { Indaiatuba } & - & \mathrm{SP} & \text { Disponível }\end{array}$ http://www.anppas.org.br/encontro anual/encontro1/gt/teoria meio ambiente/phili ppe\%20pomier\%20layrargues.pdf . Acesso em dezembro de 2010.

LAYRARGUES, P. P. Do ecodesenvolvimento ao desenvolvimento sustentável: evolução de um conceito? Revista Proposta, Rio de Janeiro, v. 24, n. 71, p. 1-5, 1997.

LÖWY, M. Ecologia e Socialismo. São Paulo: Cortez, 2005.

MANACORDA, M. A. Marx e a Pedagogia Moderna. Campinas, SP: Editora Alínea, 2007.

MARTínEZ ALIER, J. El Ecologismo de los Pobres (Conflictos Ambientales y Lenguajes de Valoración. Barcelona: Icaria/Flacso, 2004.

MCKINSEY\&COMPANY. Caminhos para uma Economia de Baixa Emissão de Carbono no Brasil. São Paulo. MCKINSEY\&COMPANY. 2010. Disponível em: http://www.mckinsey.com.br/sao paulo/carbono.pdf. Acessado em fevereiro de 2011.

MÉSZÁROS, I. A educação para além do capital. São Paulo: Boitempo, 2005. . Para além do capital. Campinas/SP; Boitempo, 2002.

PLATONOW, V. Catadores de Gramacho temem perder o sustento com o fim do lixão. Agência Brasil. 27 nov. 2011. Disponível em: http://correiodobrasil.com.br/catadores-de-gramacho-temem-perder-o-sustentocom-fim-do-lixao/215237/. Acesso em 10 de fevereiro de 2011.

VERDADE Inconveniente: Um Aviso Global. Direção: Davis Guggenheim. Roteiro: Lawrence Bender, Scott Burns, Laurie Lennard e Scott Z. Burns. Intérpretes: Al Gore. Lawrence Bender Productions / Participant Productions, 2006. 1 filme (100 min), son., color. 